\title{
Agro-Morphological Diversity (Qualitative Traits) of Oryza sativa L. Cultivated in Paiyunpata Village, Baglung, Nepal
}

\author{
Hom Nath Pathak ${ }^{1 *}$ \\ Department of Botany, P.N. Campus, Pokhara, Nepal \\ *Corresponding Author \\ homnpathak@gmail.com
}

\begin{abstract}
The study was carried out in Paiyunpata, Baglung-13, which lies in the southern part of Baglung Bazaar, Central Nepal. The main objective of the present study was to study the agro-morphological traits of rice varieties cultivated in the study area and make easy ways for germplasm conservation. Direct observation and measurements were carried out to collect primary data.Agro-morphological characters of 19 landraces of rice in the study sites were measured in terms of qualitative characters and made ways easy for germplasm conservation. Besides, the varied landraces may be suggested to breeding for crop improvement, but patents should be that of the community.
\end{abstract}

\section{Keywords}

Rice, landraces, germplasm conservation

\section{Introduction}

Rice (Oryza sativa L.) is probably one of the oldest food crops grown from ancient times in Asia. The cultivated form of rice Oryza sativa L probably originated in moist southern slopes of the Himalayan foothills and distributed to different parts of Asia, Europe, and Africa (Shahi 1979; Vavilop 1930; Moringa 1968; anonymous 2006). Rice is the primary agricultural crop of Nepal, as well as in the world. The main diet of the Nepalese people is also rice. It grows in the diverged eco climatic ranges of Nepal at different altitudes from Terai, $67 \mathrm{~m}$. asl. to hill region, up to $3050 \mathrm{~m}$ asl. altitude in the "Hit-Siza" area of Jumla district (Shahi, et al., 1982). Rice plant varies in morphological, physiological, chemical and genetic properties, thus creating rich biological diversities of contrasting characters in that no other parts match in the plant kingdom. In Nepal, $55 \%$ of cultivated land is covered with rice. Low land rice contributes $91 \%$, whereas 9 percent is cultivated in upland condition. Rice is cultivated in Nepal since the Vedic time (Mallick, 1981; Hu, et al., 2014). Almost Nepali uses rice as a staple food. It has high nutrient content with about $90 \%$ carbohydrates, $8-10 \%$ proteins, $1 \%$ fat, and $1 \%$ minerals. Besides food values, it is a source of phosphoric agent, lubricant, confectionaries, beverages, etc. ( Pathak 2006).

Crop diversity is affected by natural selection as well as by farmer's selection of agromorphological traits and management (Yadav et al., 2001). Different varieties of rice are cultivated for their various uses and adaptability to the local environment. Exploration of these local varieties and their habitat is essential for their conservation. The varietal improvement/selection process is replacing indigenous landraces, resulting in loss of genetic resources (Adhikari et al., 1994). The primary aim of the study was to collect the agromorphological diversity and making ways easy for germplasm conservation of the local landraces of rice from Paiyunpata, Baglung.

The morphological characteristics of these different rice varieties may help to recognize these landraces from other landraces. Therefore, morphological characteristics and their variability will be studied for their identities in villages, country, and abroad. These various morphological characters include the height of the tiller, internodal length, presence of awn, apiculus, no of tillers, no of grains per inflorescence, threshability, lodging effect, etc. A local variety of rice is the property of the local people. Any type of development of 
a hybrid variety of rice may be produced from these local varieties by hybridization techniques. The income from the hybrid should be of that of the community from where it is collected. To claim the patent of the local people, it should be recognized by the scientific community. The study of the agro-morphological characteristics of the rice varieties will add some of the essential aspects of this regard. A preliminary study revealed that there was cultivation of 23 landraces of rice in the Paiyunpata village development committee (VDC) area of Baglung district (Pathak and Paudyal 2008). Therefore, this study intended to study agro-morphological characters of these landraces under conventional environment cultivation. The results of this study would be essential to understand the relative importance of each landraces for use in varietals improvement programs.

\section{Study Area}

The study was carried out at the Paiyunpata village of Baglung district, Nepal. There were 1,347 households in Paiyunpata VDC. The total population was 5,041there (CBS 2012). The main occupation of the people was farming. The main food crops in the area were rice, wheat, maize, and millet. Animal husbandry was the prevalent agricultural practice of the inhabitants. The area lies in the sub-tropical region with the SchimaCastanopsis forest as major natural vegetation (Chaudhary 1984).

About two-thirds of the land is under rice cultivation in the study area. Almost all rice fields are irrigated; very few cases are rain-fed. The cultivation system is based on subsistence farming. Commercialization is very rare. Most of the farmers cultivate local landraces of rice.

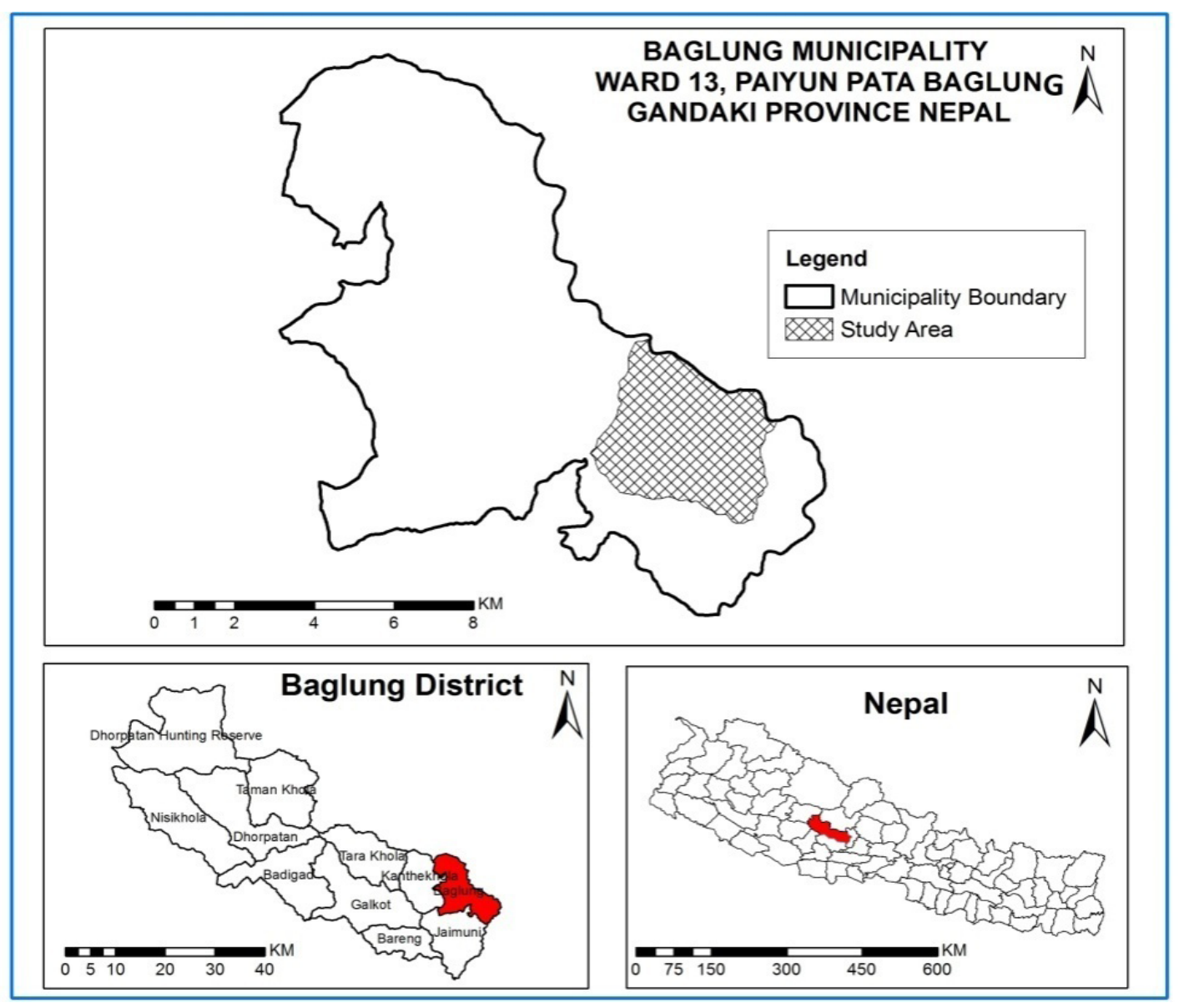

Fig. 1. Map of Paiyunpata village in the Baglung district of Nepal. 


\section{Methodology}

Rice field for seedbed was ploughed once during winter. It was ploughed, and the soil was made finer. Pebbles, if any, were removed and made ready for seedbed preparation.

Finally, the field was ploughed mixing compost fertilizers sufficiently. Nineteen plots were prepared for possible landraces of rice (i.e., Anadi, Bhatte, Rause, Kode gudura, Bhainse gudura, Aanga, Tangale, Jarneli, Gauriya, Nepale, Kathe jhinuwa, Sinjali, Ramani, Rato patle, Gola, Khate, Dauthe, Resali and Ekle). Seeds were sown and mulched with soil from the top to prevent the picking up of the rice grains by birds and ran away by water. Ricefield was prepared on farmers' way. Plots were prepared, and every rice seedlings were planted in $20 \times 20 \mathrm{~cm}$ apart from one another.

Rice descriptor was used to collect data for quantitative and qualitative characters. The quantitative characters include several tillers per hill, plant height, panicle length, 100-grain weight, culm length, number of culms, grain length and width, etc. The qualitative characters include the presence or absence of awn, color of apiculus, threshability, lodging effect, etc. To obtain data on agro-morphological diversity among the landraces from the study area, the IPGRI rice descriptor was followed. The descriptive research design was employed in this study of the qualitative type of agro-morphological diversity of rice landraces from the Paiyunpata village of Baglung district.

\section{Result}

About 27 different characteristics, including qualitative and quantitative characteristics, were observed.

\section{Qualitative characters}

Different qualitative characters of rice landraces were observed and analyzed and presented in a histogram. Qualitative characteristics include blade pubescence, blade angle, blade color, basal leaf sheath color, flag leaf angle, ligule color, collar color, auricle color, internode color, lodging effect, panicle type, panicle exertion, panicle straight or droopy, threshability, grain awning, lemma, palea color. All blade pubescence was glabrous (100\%), as in fig 1. Regarding blade pubescence, no hairy blades were found.
According to IPGRI's rice descriptor, the blade angle was categorized in angled, drooping, and horizontal. Blade angle has diverged type. It was angled (89.47\%), Drooping, and Horizontal (5.26\%) each (fig: 2). Out of nineteen, one had drooping, one horizontal and rest 17 had angled blade.

Blade color was of four different types, i.e., Green, Brown, Purple, and Yellow. Blade color also diverged i.e., green (47.36\%), Brown (10.52\%), Purple (10.52\%), and yellow (31.57\%), as in fig: 3. The Basal leaf sheath value was categorized into Green, Straw, and Purple type. The Basal leaf sheath color was green, straw color, and purple $26.31 \%, 63.15 \%$, and $10.52 \%$, respectively (fig: 4). Five, twelve, and two landraces contained Green, Straw, and Purple basal leaf sheath, respectively. Flag leaf may be horizontal, erect, or angled. Flag leaf angle was a horizontal type $(10.532 \%)$, erect $(84.21 \%)$ and angled (5.26\%). Horizontal in two, erect in sixteen and angled, was found in one landrace. The ligule color was white in all observations.

Collar color was white, brown or black $84.21 \%, 10.52 \%$ and $5.26 \%$ respectively.(fig:7). Collar color was white, brown, and black in sixteen, two, and one variety, respectively.

Auricle color was white, black-brown, or absent. White was (36.84\%), Black (5.26\%), Brown (15.78\%), and absent $42.10 \%$ (fig; 8 ). It was White in seven landraces, Black in two, Brown in two, and absent in the rest of the eight landraces. Internode color was straw color in all cases (fig: 9). Lodging effect was $31.57 \%$, and absent $68.42 \%$ (fig: 10 ). It was found in seven landraces and absented in the other eleven landraces. Panicle type was $21.05 \%$, intermediate, $26.31 \%$ in compact and open $52.63 \%$ (fig; 11). A panicle type was intermediate in ten landraces, compact in five, and opened in four other landraces.

Panicle exertion was categorized into well exerted and partly exerted. The well-exerted type was found in eleven varieties and partly exerted in the rest of the eight varieties. Panicle exertion was of two types -well exerted $(42.10 \%)$, or partly exerted $(57.89 \%)$, as in fig 12 . Panicle straight in $57.89 \%$ and droopy $42.10 \%$ (fig: 13 ). Eight landraces contain straight panicles, and the 
other twelve contain a droopy type of panicle. Threshability found in three categories - easy $68.42 \%$, intermediate $26.31 \%$, difficult in few cases $(5.26 \%)$ as in fig: 14 . Threshability was easy two types in almost varieties (13 landraces)and intermediate in five types and reported difficulty in Kathe jhinuwa. Awn was present in rice grains -short $10.52 \%$, long $26.31 \%$ and absent in $63.15 \%$ (fig: 15). Grain awn was present in three landraces as short in Tangale, Kathe jhinuwa, and Gola. Long awn was present in three varieties i.e., Dauthe, Anadi, and Sinjali. It was absent in the other twelve landraces. Lemma and palea color in grains were found to be white, Brown, Pink,

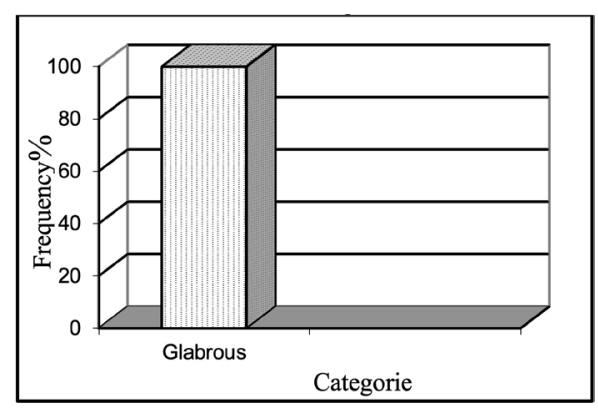

Fig.1.BladePubescence

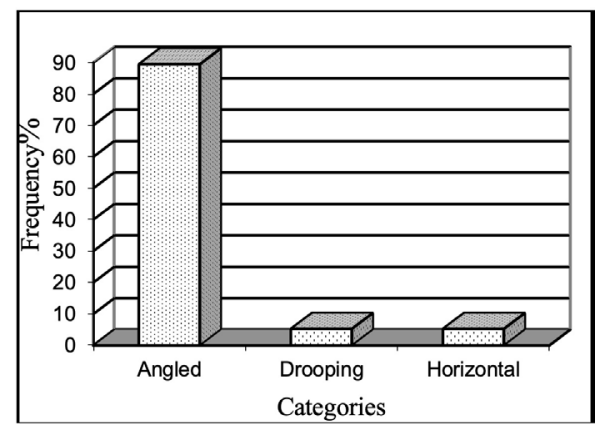

Fig. 2. Blade angle

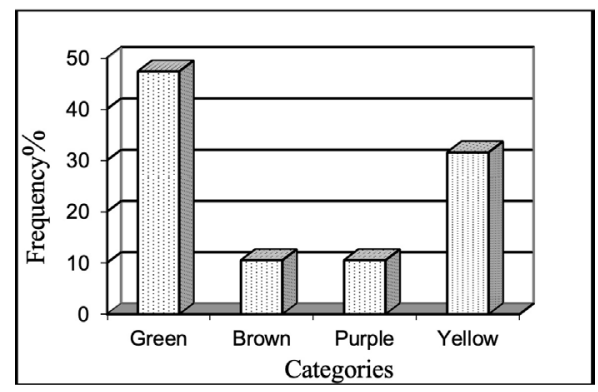

Fig. 3 Blade color and White Brown as 68.42.68\%, 21.06\%, 5.26\%, $5.26 \%$, respectively. Lemma and palea color were observed white in thirteen landraces brown in the other four and pink in two; Aanga and Ramani. White and brown type of lemma palea color was absent in one.

\section{Discussion}

Agro-morphological traits of rice are essential factors affecting biotic stress on rice development and to develop a new strategy for varietal improvements (Ndur, et al., 2016). Our result slowed that farmer in the study site used to cultivate 19 landraces which were local to the

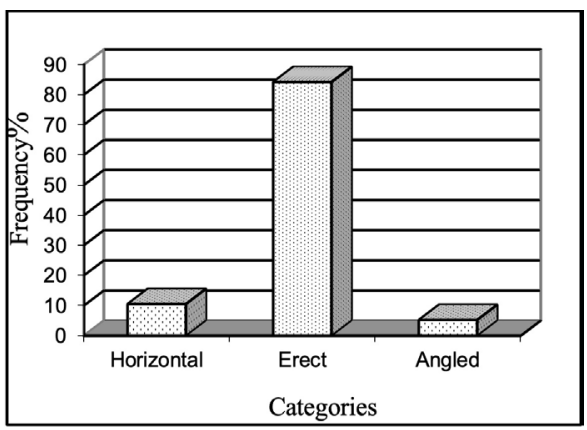

Fig. 5. Flag leaf angle

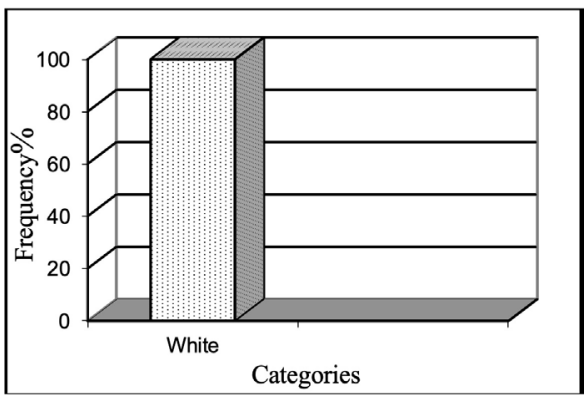

Fig. 6 Ligule color

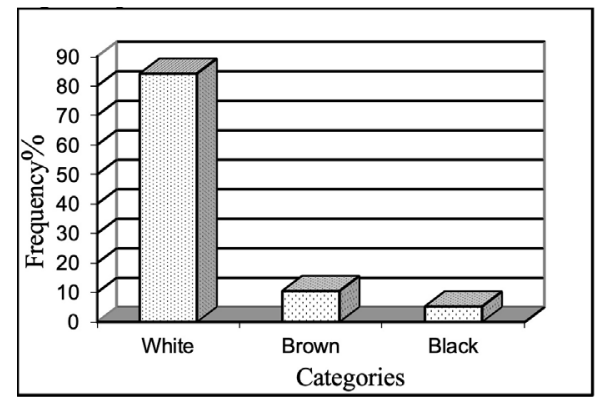

Fig. 7 Collar color 
study area. The agro-morphological variabilities provide baseline information for planning in-situ conservation of the landraces and germplasm conservation. Rice diversity in mid-hills was due to altitudinal variations, environmental heterogeneity, and diverged agro-ecosystems (Roy et al., 2016). We found that similar names showed close relationships among the landraces. It was noted that farmers cultivated rice varieties according to their needs (Nepale was cultivated for early harvesting purposes during Dashain). Use values and healthy grain and straw qualities. A similar study with a graphic representation of qualitative characteristics was carried out in a

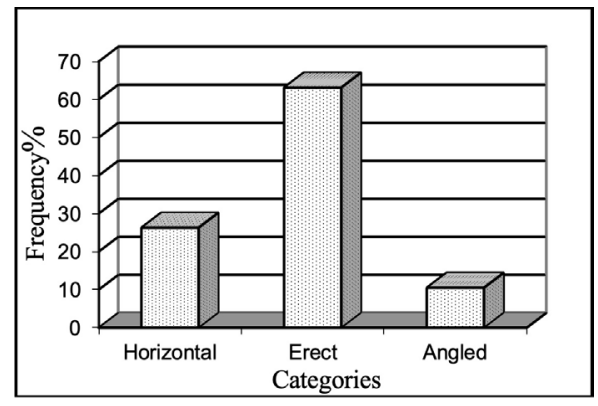

Fig. 4 Basal leaf sheath

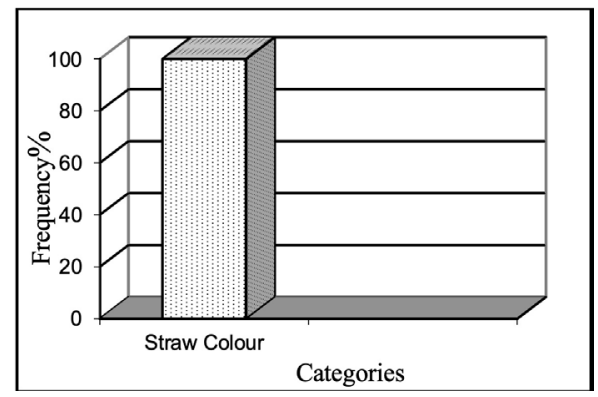

Fig. 9 Internode color

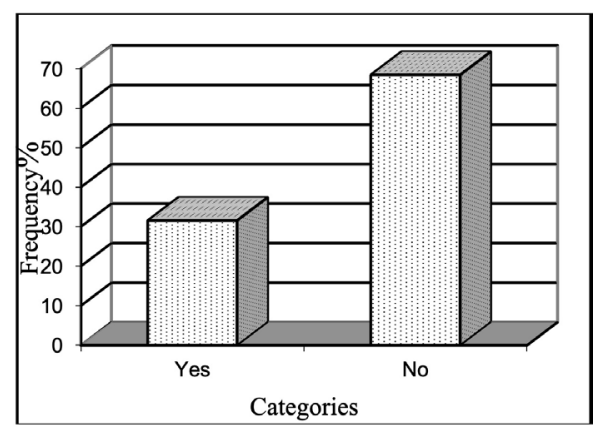

Fig. 10 Lodging effect study by Yadav et al., (2001) and similar by Tiwari et al., (2001).

Out of the agro-morphological traits provided by IPGRI blade pubescence, blade angle, blade color, basal leaf sheath color, flag leaf angle, ligule color, collar color, internode color, lodging effect, panicle type, panicle exertion, threshability, grain awning, lemma palea color, were observed that were also responsible for variability among the local landraces. Tanglae landrace was found to be cultivated in the study site and nowhere else, according to the farmers of the area.

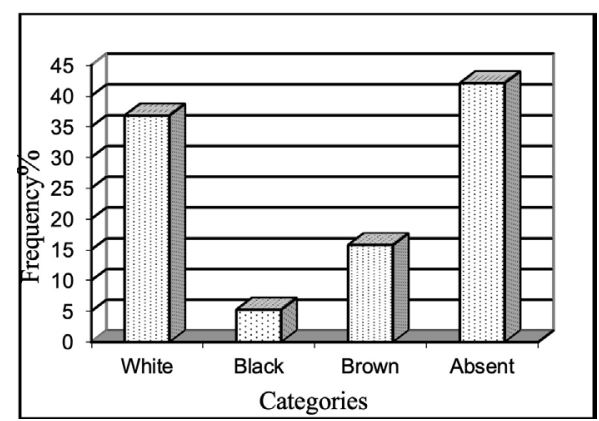

Fig. 8 Auricle color

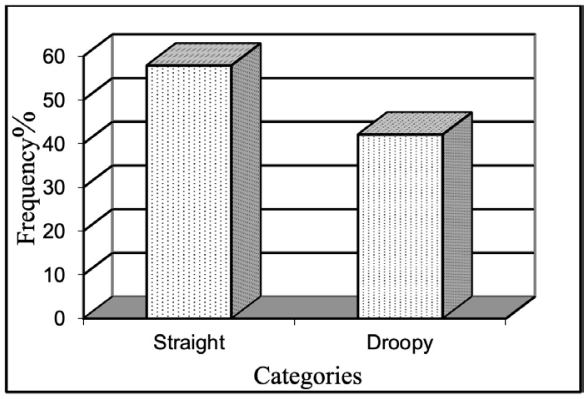

Fig. 13 Straight or droopy

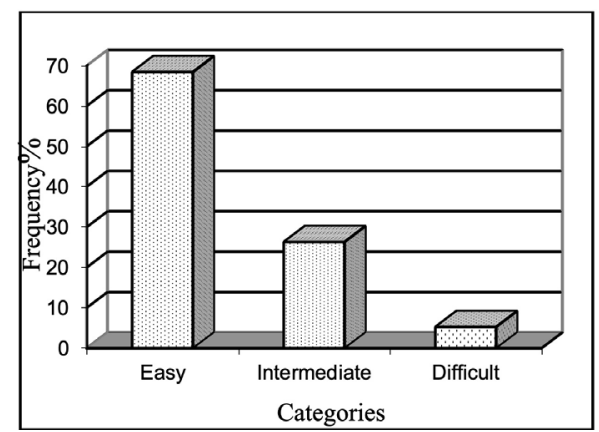

Fig. 14 Threshability 


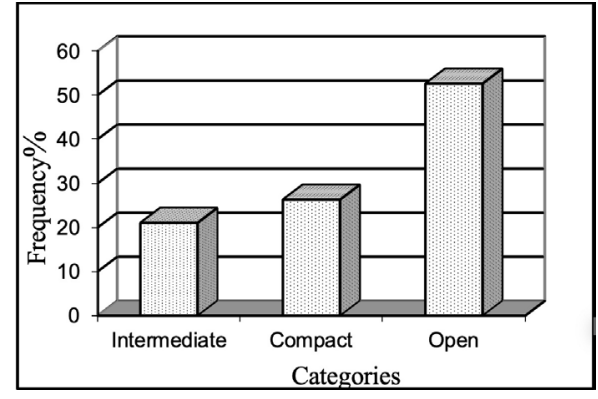

Fig. 11 Panicle type

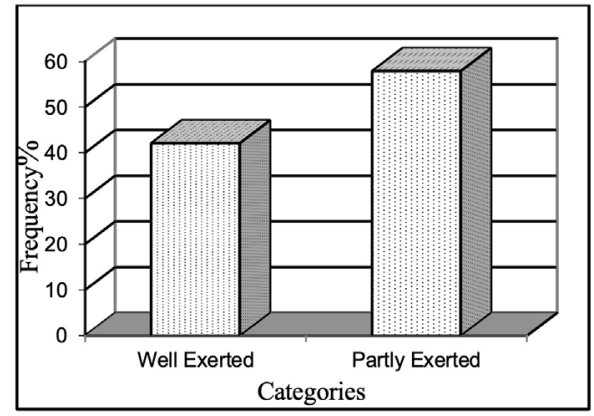

Fig. 12 Panicle exertion

\section{Conclusion}

The present study carried out in Paiyunpata, Baglung-13 for agro-morphological diversity among different landraces revealed the following salient features:There were about 19 landraces of rice cultivated in the VDC since a long before. There were 16 qualitative characters studied to document the agro-morphological traits. These rice landraces with different genotypes can be exploited for germplasm conservation and breeding purposes. The most different genotypes may yield a tasty variety for such an area. Tangale landrace was found to be cultivated in the study area and peripheral VDCs from a long time ago and known by Balewali Gudura. They are not cultivated elsewhere. The people of the area may be associated with the patent on it and can be benefited from its exploitation during breeding of any type. Findings from the study have implications for utilization at present and germplasm conservation for the future. Genetic diversity, as well as agro-morphological diversity, has been maintained by the local farmers. These diversities are due to cultural, climatic factors and soiltypes too.It is encouraging for in-situ conservation as well.

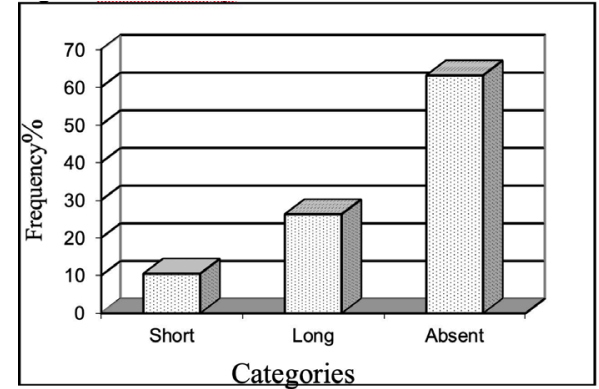

Fig. 15 Grain awning

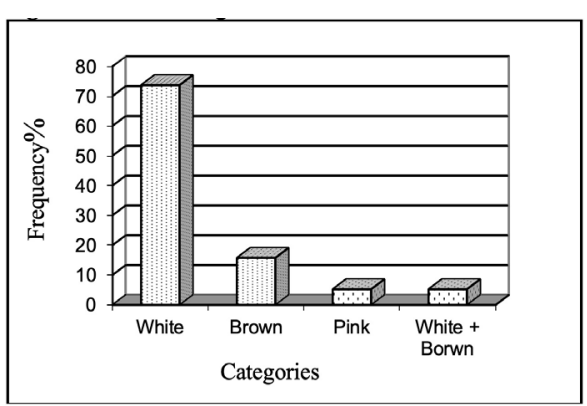

Fig. 16 Lemma and Palea color

\section{Acknowledgments}

The author is thankful to Nepal Academy of Science and Technology (NAST), for providing funds for this research. I would like to thank Prof C.B. Thapa, Ph.D., Department of Botany, P.N. Campus, T.U., for supervising the research work. I would like to acknowledge Dr. B.B. Shrestha, CDB, T.U. for comments and suggestions and Dr. C.B. Baniya, CDB, T.U. for the comments on the manuscript, and an unknown reviewer.

\section{References}

Adhikari, N.P. Palikhe, M.M. and Devkota, R.N. 1994. Status of Rice, Maize And Wheat Genetic Resources in Nepal. In: Upadhyaya, Saiju, Baniya, and Bista (eds.).Plant genetic resources in Napalese perspectives, NARC, and IPGRI.

Anonymous, 2006. Encyclopedia.com. Retrieved from https://www.encyclopedia.com/plants-andanimals/plants/plants/rice at 10.08 10/06/2018

Bajracharya, J., Steele, K.A., Jarvis, D. I., Sthapit, B. R. and Witcombe, J. R.2006. Rice landrace diversity in Nepal: Variability of agro-morphological traits and SSR markers in landraces from a high-altitude site. Field crops research. 95,327-335.

CBS (2012) Baglung District Central Nepal Central, 
bureau of statistics, Thapathali, Kathmandu

Chaudhary, R.P., 1984. Vegetation Pattern In Majupuria, TC (ed). Nepal Nature's Paradise, White Lotus Company Ltd, Bangkok, Thailand.

Mallick, R.N., 1981.Rice in Nepal. Kala Prakashan, Kathmandu, Nepal.

Moringa, T., 1968. Origin and geographical distribution of Japanese rice. JARQ 3, 1-5

Panta, K. P., Gautam, J. C, and Wale, E. 2001. Valuation of Rice Diversity in Nepal: A Traitbased Approach. The Economics of Managing Crop Diversity on-farm. In: Edilegnaw Wale, Ada G Drucker, and Krerstin K. Zander. Earthscan, London (eds.). Case studies from the Genetic Resources Policy Initiative.

Pathak, H.N., 2006 Medical Botany. Ozone Books, Pokhara, Nepal.

Pathak, H.N. and Poudyal, G.P. 2008. Inventory on Ethnobotanical Knowledge on Oryza Sativa L Cultivated in Paiyunpata VDC Baglung. A Research Report Submitted to Research Committee, Prithvi Narayan Campus, Pokhara, Nepal.

Shahi, B.B., and M.H., Hell. 1979. Low-Temperature Problem and Research Activities. In: Nepal, IRRI, Report of a Rice Cold Tolerance Workshop, Los Banos, Philippines.

Tiwari, R.K., Baniya, B.K., Bajracharya, J., Joshi B.K., Joshi, K.D., Khatiwada, S.P., Upadhyaya, M.P., and Sthapit, B.R. 2001.On-Farm Characterization Of Rice Land Races And Population Structure of Jhinuwa In Begnas, Kaski. In: B.R. Sthapit, M.P. Upadhyaya, B.K. Baniyaand B.K Joshi (eds). OnFarm Management of Agricultural Biodiversity Nepal. Proceedings of National Workshop. 24-26 April.

Vavilov, N.I., 1930. Studies of the origin of cultivated plants. Bull.Appl.Bot.Plant Breeding 16.

Yadav, R.B., Chaudhari, P., Bajracharya, J., Rijal, D. K., Khatiwada, S. P., Tiwari, R. K., Yadhav, R. K., Upadhyaya, M. P., Mudwari, A., Baniya, B. K., Gupta, S. K., Gautam, A. K. and Joshi, B. K. 2001. Agro-Morphological Diversity in Rice Landraces of Bara and Kaski Eco sites. In: B. R. Sthapit, M. P. Upadhyaya, B. K. Baniya, and Joshi B. K (eds). On-Farm Management of Agricultural Biodiversity Nepal. Proceedings of National Workshop, 24-26 April.

Hu, C., Shi. J., Quan, S., Cui, B., Kleessen, S., Nikoloski, Z., Tohge, T., Alexander, D., Guo, L., Lin, H., Wang, J., Cui, X., Rao, J., Luo, Q., Zhao, X., Fernie, A.R., and Zhang, D. 2014. The metabolic variation between japonica and indica rice cultivars as revealed by non-targeted metabolomics.Sci Rep,4,5067, DOI: 10.1038/ srep05067. 